\title{
An Investigation into Gender Disparities in the Field of Computing
}

\author{
Abir Jaafar Hussain ${ }^{1}$, Laura Connell ${ }^{1}$, Hulya Francis ${ }^{1}$, Dhiya Al-Jumeily ${ }^{1}$, Paul Fergus ${ }^{1}$ Jan \\ Lunn ${ }^{1}$ and Naeem Radi ${ }^{2}$,
}

\author{
${ }^{1}$ Applied Computing Research Group \\ School of Computing and Mathematical Sciences \\ Liverpool John Moores University \\ Liverpool L3 3AF, UK \\ ${ }^{2}$ Khawarizmi University College Sheikh Saeed Bin Mohammed Al Nahyan Tower \\ 2nd Street, Tourist Club Area \\ Abu Dhabi, United Arab Emirates \\ a.hussain@1jmu.ac.uk, h.francis@1jmu.ac.uk d.aljumeily@1jmu.ac.uk,p.fergus@1jmu.ac.uk,n.radi@khawarizmi.com
}

\begin{abstract}
This paper explains the reasons as to why there is under-representation of females computer science. Recent research undertaken at a British University focused on gender imbalance amongst academic staff in the Faculty of Technology and Environment, Liverpool John Moores University. The paper presents evidence that suggests the significance of identifying female role models in the field as a precursor to improving the current gender imbalance amongst academic faculty. In addition, the paper suggests the importance of addressing the negative stereotypical images related to the discipline and suggests the importance of identifying barriers to access and mobility females encounter in the field. The results of this initial investigation demonstrate the subjective belief amongst female academic faculty that in the School of Computing is dominated by male academics. Further, this belief pattern manifests itself in a perceived lack of motivation for promotion in the School. It can be concluded that the deeply entrenched belief system determines a lack of attempts to seek and secure promotion amongst all grades of female faculty. The paper proposes recommendations which the School could adopt to improve recruitment and retention of female academic staff and students.
\end{abstract}

Keywords-computer science, female underrepresentation, women and computer science

\section{INTRODUCTION}

It is a well-known problem that female representation in computing education has been in decline for the past 30 years, as a result males have become the dominant gender enrolling on computing courses and successfully achieving academic qualifications in the subject. The research has been carried out at a British University between 2014 and 2015 and focused on gender imbalance amongst academic staff in the Faculty of Technology and Environment, Liverpool John Moores University, UK.
The research output suggests males have become the dominant gender enrolling on computing courses and successfully achieving academic qualifications in the subject.

(Misa, 2010, p. 5) explains that even though in the history of computing education women successfully completed computing education courses and obtained jobs as computer professional, in the mid-1980s "the proportion of women studying computing actually began falling and has continued to fall, steadily, all the way through to present."

Research indicated that in the UK $14.84 \%$ of females achieved a computer science bachelor degrees compared to $85.16 \%$ of male graduates

Computer Science is not the only field that is presented with the problem of the gender gap; females were part of the minority in mechanical engineering which is also a STEM (Science, Technology, Engineering and Mathematics) discipline. Females represented only $8.31 \%$ of the national figures during 2012-2013. Whereas the male mechanical engineering graduates held a larger proportion representing $91.69 \%$ of the national average.

Many companies are faced with the challenge of not only recruiting women in IT but also retaining them as (Herscher, 2014) states "fifty-six percent of technical women leave tech companies within 10 years - more than double the dropout rate for men. This can be damaging for tech companies especially after investing a lot of time and money in training female employees yet when faced with the 'fight or flight' moment they decide to leave. A report by (NCWIT, 2010, p. 17) explains "nearly half the women who leave the SET sector continue to use their training in other sectors - just not for the private sector or the company they leave."

The females who do pursue careers in the IT industry are discriminated against as they face being paid less than their 
male counterparts. A report by (NCWIT, 2010, p. 18) explicates "the highest paid industry for technical women was banking and finance, where the average female salary was $\$ 80,322$, however technical men in banking and finance averaged higher salaries at $\$ 89,549$, making the gender gap for the industry approximately $10 \%$." Along with being promoted more slowly than men, this could deter women from pursuing a career in the field and be partly the reason females decide to make an exit from the IT industry midpoint of their career.

A report by (Castillo, et al., 2014, p. 13) suggests the potential reason females aren't promoted as much as males is because "peers are often required to nominate a colleague to a highlevel position and STEM field are male dominated areas and there is a tendency to discriminate against women when considering promotion." This type of sexual discrimination is against the law and if less favourable treatment is being given to women than a man, it could result in the effected individual filing a law suit against their employer. Unfortunately, stereotypical images exist in the field of computing and some employers may have different ideas as to what women's work is and what men's work is.

There is a dearth of females in computer science, along with the barriers females face entering the field, the reasons for this are due to the lack of female role models and the conforming of the negative stereotypical images related to the subject. As the field of technology continues to grow, it is vital females are part of this creating a gender diverse discipline which can successfully contribute towards a counties economy.

The reminder of this paper is organized as follows. Section II will discuss the reasons why female should follow career in computing. Section III will outline the barriers females experience when entering the field of Computing.

\section{FEMALES AND THE FIELD OF COMPUTING}

In order for the countries to economically compete in the world, it is vital they possess a strong workforce with a technical skill base consisting of both talented male and female individuals. It is well known worldwide there is a discrepancy between the number of male and female graduates from computer science and the computing workforce. (Pollack, 2012) states "despite decades of progress in higher education and the workplace, gender bias in STEM fields inhibits many talented women and girls from entering STEM careers."

The Bureau of Labor Statistics (BLS) in USA estimates 1.4 million new jobs in computer science by 2020 (Koebele, 2015). It is significant the female populations are part of this talented technological workforce. Alongside the economic benefits for a countries economy, a gender diverse workforce can have a number of other advantages. Gender diversity can provide better problem solving skills as men and women are known to have different viewpoints and ideas which overall can help improve performance. A study by University of Pennsylvania indicated that men are better learning and performing with single tasks on the other hand women tend to be better at multitasking and problem solving (Wyatt, 2014).

Gender diversity also provides a larger talent pool and gives companies access to resources including multiple sources of information and wider industry knowledge. (Wyatt, 2014) states "any business that is reluctant to hire women whether in general or for high level positions is missing out on over half the talent pool." A gender balanced company is more likely to encourage the recruitment of women within their workforce and help improve the retention of their current employees as employee morale will tend to be good throughout the company and therefore staff turnover will be low.

A lucrative career in computer science offers females, as well as males, a high pay salary than those fields dominated by women as National Association of Colleges and Employers Spring 2011 Salary Survey showed "new graduates with bachelor degrees in computer science were offered an average starting salary of $\$ 63,017$ (Career Builder, 2011) A computer science profession also presents graduates with the opportunity in pursuing a career in a wide range of industries from banking to healthcare leading the way with cutting edge technologies. (Career Builder, 2011) explains "computer scientists are sought after in pretty much every industry and in a wide range of capacities. A computer science degree can lead you to fulfilling, well-paying careers, which is something that is a rarity in the current state of the economy."

(Miller, 2014) states "a lack of diversity across the scientific community represents a loss of larger potential talent for the UK. Not only does this limit the UKs competiveness and prosperity, it also curves the vitality and creativity of the wider scientific workforce." Therefore it is vital that Government, educators, businesses and women's organization all play a major part in recruiting and retaining female in STEM to help create a gender diverse workforce.

Attempts have previously been made by the UKs Science and Technology Committee to help improve the gender imbalance in STEM fields, however progress has been slow. "On 6th February 2014 the committee published its sixth report of session 2013-2014, women in scientific careers (Miller, 2014)." In response to this the committee received a memorandum agreeing to continue to promote and support equality and diversity at all levels. Working together with educators, businesses, academics and campaigners, the governments have promised to implement the recommendations put forward by the committee.

Unfortunately following the 2010 review government funding for the UK resource center which provided practical support for women in science, engineering and technology was not renewed and it ended in April 2011. However, after a round table on 17th December 2013, at 10 Downing Street in the UK, attended by educators, businesses, academics and campaigners, the government have asked "organizations to work together in a national partnership-led campaign of activity to boost female participation in technology and engineering (Miller, 2014).”

The government is fully committed to supporting the Your Life campaign "a three-year campaign to ensure young adults in the UK have the math's and science skills needed to succeed in the 
current competitive global economy whilst triggering employers to recruit and retain this talent (YourLife, 2015)."

The National Center for Women and Information Technology (NCWIT) are also working towards correcting the gender imbalance in the subject of computing by encouraging reform across full education and career spectrum. (NCWIT, 2015) "programs and campaigns support policy reform in k-12 computing education, improve the visibility of women in computing, encourage high school girls to pursue a computing career and shine a spotlight on the successes of entrepreneurial women."

Businesses including IBM are very keen on recruiting more females in STEM in particular employing females in computer science careers. The company is currently running a campaign called IBM Innovation 26x26 in response to the figures of women holding just $26 \%$ of roles in certain tech fields.

\section{THE BARRIERS FEMALES FACE ENTERING THE FIELD OF COMPUTING}

Along with the lack of support female computer scientists receive due to a small number of female computing role models and the threat of confirming the stereotypical images of a computer scientist, women are also faced with a number of barriers when entering the field of computing. Even before females enter the field of computing a lot of them are faced with gender bias in socialization both at home and in school and are expected to conform to the social norms of being a woman. Some females even have to deal with pressures from their family and friends regarding what career path they should take. A computer scientist can be viewed as "an antisocial white male, highly skilled and intelligent, with little attention to personal hygiene (Misa, 2010, p. 268)." This stereotypical image can present females who are happy to carry out a profession as a computer scientist with challenges as they may be considered to be operating outside the norm which may be seen as unfeminine conduct of them. (Spertus, 1991, p. 1) explains "girls and women are subject to societal pressures to stay away from such subjects or to accept themselves as "unfeminine". Academically successful women are generally seen as being less attractive and less happy than less highly achieving women."

The negative image of a computer scientist is known to be lacking of social skills which is something a female doesn't, in actual fact females are believed to have great social skills and so are deemed not suited to a role in computing. Instead females are seen to be more suited to the job of a nurse or a school teacher. This type of sex stereotyping can be seen as early as preschool, (Spertus, 1991, p. 5) explains "by the age of three years, most children know that girls will grow up to clean the house, be a nurse, or be a teacher and boys will grow up to be boss."

Those females who do decide to rise to the challenge of the social pressures do actually enter the field of computing, but they are less likely than men to enter tech-intensive industries. The statistics in Figure 1 show only $18 \%$ of those MBA graduates, who chose business roles as their first post were female, compared with $24 \%$ of males. Unfortunately for those females who are successful in obtaining a job working in tech industry they are still faced with barriers in their working environment. (Lindberg, 2014) explains "if women do complete their degrees in computer science they still face hostile work environment prone to sexual harassment and double standards."

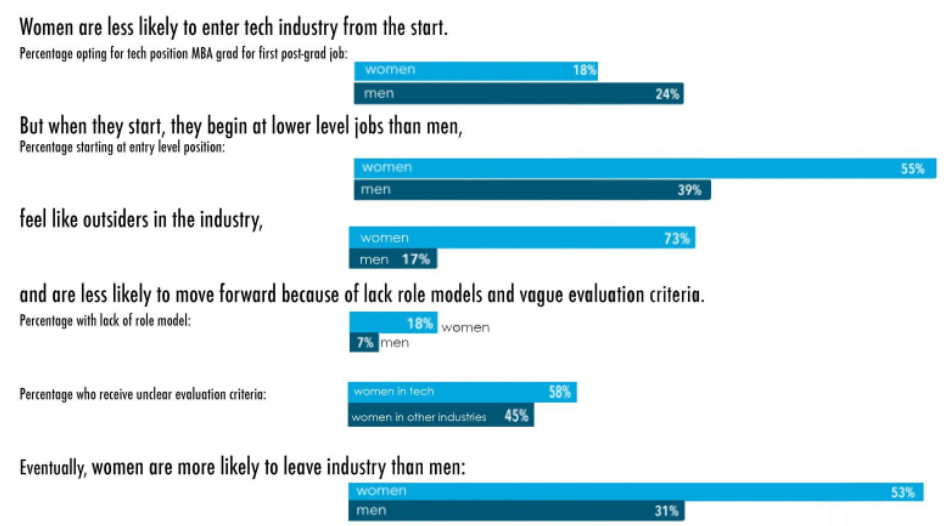

Fig.1. The gender divide in Tech industries. [13].

A report by (MPR news, 2013) discusses the behavior of males that women have to deal with during their careers in the tech industry. One female who lost her job in the tech industry after speaking out; complaining about the rude manners of males at a tech conference expresses how she feels about attending technology conferences. "When you're the only person that looks like you, it can feel kind of awkward. No one has to actually say anything to the point of 'you don't belong here' but you certainly feel it."

When women do begin their careers in the tech industry they begin at lower level jobs than men even though they have achieved the same academic qualifications. Figure 1 shows $55 \%$ of females starting at entry level positions begin their careers working in lower positions than their male counterparts as only $39 \%$ of males start their career working in lower positions. The limited resources available for females such as the lack of female role models, mentors and networks can affect them when promoting their skills and advancing in their careers by obtaining a senior role in the tech industry. Even when this support is available for them, females can be quite reluctant to take advantage of it as they tend to have the perception along with males that females need extra help in order for them to be successful.

Figure 1 shows $73 \%$ of females feel like outsiders in the tech industry compared to $17 \%$ of males. Females are more likely to feel isolated in the tech industry working in such a male dominated environment, some females believe they are not acknowledge and taken seriously by their males counterparts. (Curtis, 2013) explains "women in IT often end up feeling like lone wolves, not only because $83 \%$ of the technology workforce is male, but also because many feel their skills are under-valued." Females are known to suffer more than men with their self-confidence which can affect their ability to 
perform well in their jobs, some females believe they don't have as many opportunities as males to contribute their ideas and when they do they don't feel valued for their technical skills and feedback that they bring to the job.

Figure 1 shows $18 \%$ of females are less likely to move forward compared with only $7 \%$ of males. The lack of female role models can have an impact on a female's career advancement as females role models can help to inoculate women against the negative images related to computing and provide them with the support and guidance to succeed in such a male dominated industry. (Misa, 2010, p. 11) states "positive role models and mentoring in the classroom and at work are crucial institutional supports." It is vital to promote successful female role models who have managed to create a work life balance pursuing a career in the tech industry alongside rearing a family, as females tend to feel more strongly than men to raise a family and are seen as the primary care. However many believe a career as a computer scientist is incompatible with this goal and therefore males are better suited to the tech industry.

Figure 1 shows after battling with barriers throughout their careers $53 \%$ of females are more likely to leave tech intensive industries in comparison with $31 \%$ of males. In a survey of 716 women conducted by (Snyder, 2014) the results showed "many women said it wasn't motherhood alone that did in their careers. Rather it was a lack of flexible work arrangements, the unsupportive work environments or a salary that was inadequate to pay for child care." This is something that businesses and governments should take into consideration and to help provide support for females who need it in order to improve retention of women within the IT industry.

\section{MethodOLOGY}

The research in this paper was gathered through an extensive review of all relevant literature relating to the hypothesis of the project. Questionnaires were created and distributed to female students in computer science. Interviews were conducted with computing lecturers in both genders.

The questionnaires were distributed to all first year female computing students during a lecture for the Introduction to Computer Programming module with the help of the module lecturer. The author also requested the module leader for Ecommerce Systems to distribute the questionnaires to a number of final year female computing students who are enrolled on the module. The main aim of these questions was to find out the number of female participants enrolled on courses within the computer science, whether the students enjoyed their university course and if they believed their school was underrepresented by female faculty staff. Over 60 female students participated in the survey.

As it can be seen from Figure 2, Information Technology \& Multimedia was the most popular course, $33 \%$ of the research participants were enrolled on this course. Information Technology \& Multimedia may be seen by female students as an exciting course that enables them develop their creative skills allowing them to create digital multimedia and internet applications. Computer Studies achieved the second highest choice as $28 \%$ of the female participants were enrolled on this course, followed by Computer Forensics at $18 \%$ and Information Systems at $10 \%$. The courses that are seen to be more technical and require students to develop on their programming skills ranked the lowest with only $8 \%$ of participants studying Computer Games Technology, 3\% studying Cyber Security and none of the participants were studying Software Engineering. Females are believed to have a negative perception of computer programmers as being male computer 'nerds' who are lacking in social skills and sit in dark enclosed rooms for hours on end writing code. This stereotypical image is known to be one of the reasons for the underrepresentation of female computer scientists as the current image of computing can deter many women from progressing in the field.

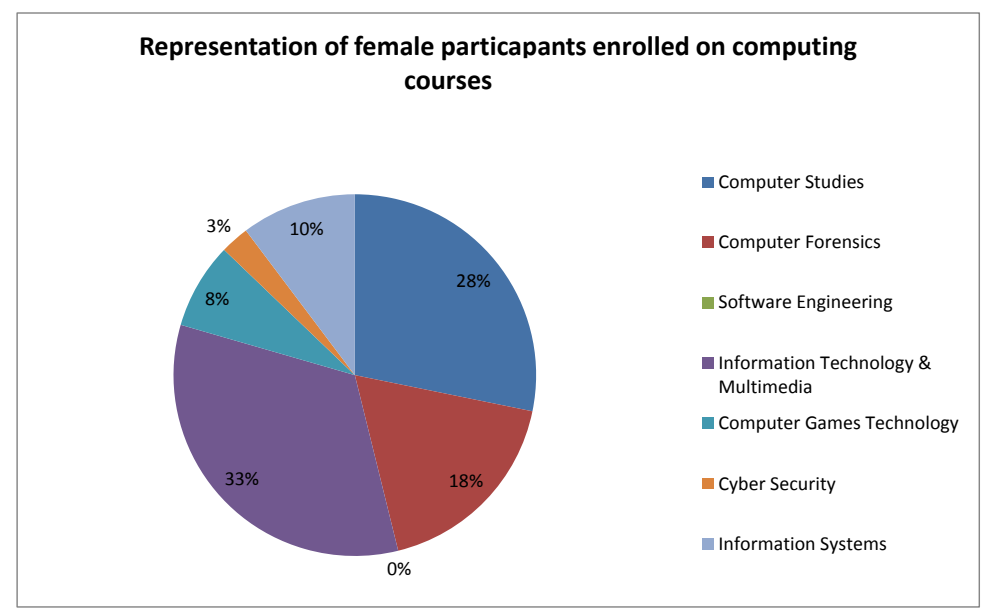

Fig. 2. The percentage of the university course female are enrolled to.

As it can be shown in Figure 3, the majority of the participants are happy with their university course, $59 \%$ of the participants think their course is interesting and $15 \%$ of the participants stated their course is very interesting. These results contradict with the CEO of YouTube statement regarding the reasons why women don't pursing computing “they don't understand why computer science is interesting - they don't think it necessarily applies to anything, and they don't associate with the people they see who are in it." (Lynch, 2015).

The participants believe the School of Computing is underrepresented by female faculty staff as $79 \%$ agreed it is, whereas the remaining $21 \%$ of the participants think the faculty is not underrepresented. These results reflect the current problem that STEM field disciplines face as their faculties are underrepresented by female academics. 
Female participants interest in their computing course

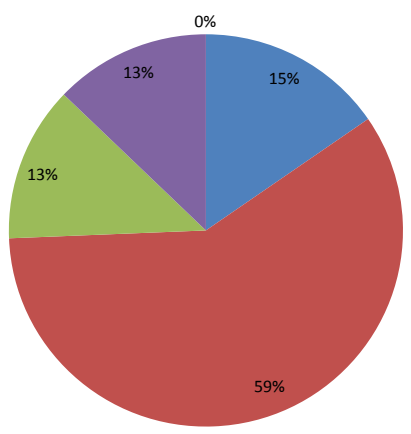

- Very interesting

Interesting

= Neutral

- Uninteresting

- Very uninterestin

Fig. 3. The perception of female students on their computing courses

In conclusion, the results from these questions revealed the most popular computing course was Information Technology $\&$ Multimedia, this course is considered to be creative and something that the female participants have a great interest in. The results also proved to be positive regarding the students interest in their university course, combined almost three quarters $(74 \%)$ found their course very interesting and interesting. The results from the computing questionnaire also reflected current discourses concerning the underrepresentation of female faculty as 79\% agreed that their school lacked female academic staff.

As for the interview, eight lectures were interviewed with 4 female and 4 male.

Interviews with female computing academic faculty were carried out and aimed to gather information about the interviewee's career and academic background and what they thought about the underrepresentation of females in computer science.

The interviewees responses varied as one of the female respondents explained they had always intended on becoming a computing lecturer, however they were not encouraged or guided to do so and instead receive a grant to become a researcher. Whereas a male respondent stated they didn't set out to become a computing lecturer, but as their career progressed they were given advice and guidance about becoming a lecturer and took this advice on board.

The female respondents all agreed that the faculty is underrepresented by female members of staff, whereas the male respondents don't feel the faculty is dominated by male faculty members of staff. This suggests as the males are not part of the minority they more than likely feel comfortable in their working environment unlike the females who are more aware of their masculine work environment.

A female respondent agreed that the current image of computing can deter many females from pursing the field as she explains many people have the view of computing as being a male profession and the stereotypical images related to the field can be off putting for females. A male respondent spoke differently about this explaining throughout his previous work experience even though females were underrepresented his female colleagues didn't seem to be put off by this.

All of the respondents believe that the subject of computing does have some aspects of mathematics related to it especially the technical side of the subject, however one respondent explained that the field of computing covers a wide variety of careers which all require interpersonal skills including communication and team work skills. The respondents also discussed how the field is lacking female role models and most of them talked about female programmers from the history of computing rather than those of this present day.

There were great responses from the interviewees when asked what strategies could be put in place to help attract females into studying computing. Responses included how lecturers should hold events at secondary schools and colleges to tell young female students that computing is actually exciting and attract them into getting involved. Another response talked about how females members of staff of the Faculty of Technology and Environment at LJMU should be promoted more and those female role models should be publicized.

The female interviewees were asked to additional questions, one of the respondents stated how they do find computing exciting because it is part of their careers and it is something they are passionate about. Another respondent explained how they don't feel the stereotype of a male nerd is unappealing to them as women because they are familiar with the image and so they haven't let this put them off progressing in the field of computing.

The interviewees responses varied as one of the female respondents explained they had always intended on becoming a computing lecturer, however they wasn't encouraged or guided to do so and instead receive a grant to become a researcher. Whereas a male respondent stated they didn't set out to become a computing lecturer, but as their career progressed they were given advice and guidance about becoming a lecturer and took this advice on board.

The female respondents all agreed that the faculty is underrepresented by female members of staff, whereas the male respondents don't feel the faculty is dominated by male faculty members of staff. This suggests as the males are not part of the minority they more than likely feel comfortable in their working environment unlike the females who are more aware of their masculine work environment.

A female respondent agreed that the current image of computing can deter many females from pursing the field as she explains many people have the view of computing as being a male profession and the stereotypical images related to the field can be off putting for females. A male respondent spoke differently about this explaining throughout his previous work experience even though females were underrepresented his female colleagues didn't seem to be put off by this.

All of the respondents believe that the subject of computing does have some aspects of mathematics related to it especially the technical side of the subject, however one respondent explained that the field of computing covers a wide variety of 
careers which all require interpersonal skills including communication and team work skills. The respondents also discussed how the field is lacking female role models and most of them talked about female programmers from the history of computing rather than those of this present day.

There were great responses from the interviewees when asked what strategies could be put in place to help attract females into studying computing. Responses included how lecturers should hold events at secondary schools and colleges to tell young female students that computing is actually exciting and attract them into getting involved. Another response talked about how females members of staff of the Faculty of Technology and Environment at LJMU should be promoted more and those female role models should be publicized.

The female interviewees were asked to additional questions, one of the respondents stated how they do find computing exciting because it is part of their careers and it is something they are passionate about. Another respondent explained how they don't feel the stereotype of a male nerd is unappealing to them as women because they are familiar with the image and so they haven't let this put them off progressing in the field of computing.

\section{DISCUSSION}

Based on our research, both male and female role models are vital in any subject as they can provide guidance during an individual's personal and professional development, helping them to make decisions that can shape the future of their lives. There are a number of successful female role models at LJMU School of Computing including the lecturers, the first year students, the industrial placement students, the final year graduate students and postgraduate students, all of who have personal achievements which others may look up to for inspiration for their own ambitions.

Working together with the university the first year female computing students could participate in a weekly question and answer session via social media platforms including Twitter and Facebook aimed at prospects female computing students who are interested in pursuing a computing degree but have concerns which are putting them off from applying to study the subject. As the first year students would have been in the same position as the prospects students the previous year they will be able to share their experiences and explain how they overcome any problems they faced during the application process and during the first year of their studies.

Female only computing club hosted by the female computing lecturers would enable the female computing students to develop their technical skills and become familiar with the programs they will be required throughout the course of their degree. Those students who decide to attend could be allocated a mentor who will be responsible for supporting and encouraging the students as well as questioning and challenging them along the way in order to point them in the right direction to progress with their development of technical skills.

The negative stereotypical images discussed in this paper have been known to deter many women from pursing the subject of computing as those women who conform to the images tend to have the perception computing is nerdy, unfeminine and not exciting. Even though it may be difficult to erase these negative images, it is possible to modify them creating more positive images which emphasis that computing actually is exciting and it is not only a masculine pursuit. The new images should show what benefits an education and a future career can have for young females interested in applying for a place on a computer science degree course.

\section{CONCLUSION}

This research aimed to discover the reasons as to why females are part of the minority in the field of computer science. Along with a literature review, the results from the research methodology was also used to indicate that despite the gender imbalance in computer science is true, female researchers and computer scientists are active in computer science and their role is significant.

The literature review provided evidence of the dramatic gender discrepancy of female participation in STEM and in particular female underrepresentation in the field of computer science.

Considering females played a major part in the history of computing, it is surprising to see there are a lack of female computer role models at this present day. Especially as these phenomenal female computing role models of the past are not known by many young ambitious computer science students, who are instead inspired by the likes of Bill Gates and Steve Jobs. The literature uncovers the importance of having both female and male role models in STEM as they can be seen as inspirations to prospects students who are looking for a figure to relate to who can provide them with the determination to succeed in being like them.

The negative images associated with the profession of a computer scientist have been known to deter females from progressing within the field of computing. The stereotypes have created a perception of computer science as being a masculine pursuit and those females who conform with this gender related stereotypical image are afraid of pursuing a computing profession as they don't want to be seen as unfeminine and geeky.

\section{REFERENCES}

[1]. Misa, T. J., 2010. Gender Codes. Hoboken: Wiley. [2]. Herscher, P., 2014. A Bad Trend in Tech: Women are Leaving (and Not Coming Back). [Online]

Available at: http://women2.com/2014/06/30/women-leavingtech/?hvid=6Fr83h [Accessed 08 March 2015].

[3]. NCWIT, 2010. Women in IT: The Facts, s.1.: NCWIT [4]. Castillo, R., Grazzi, M. \& Tacsir, E., 2014. Women in Science and Technlogy. What does the literature say?, s.1.: Inter-American Development Bank.

[5]. Pollack, W., 2012. Recruiting and Supporting Women and Girls in Science, Technology, Engineering and Mathematics (STEM) Careers. [Online]

Available at: http://www.huffingtonpost.com/wendypollack/stem_b_1397968.html [Accessed 1st April 2015]. 
[6]. Koebele, J., 2015. Scholarships, Colleges and Careers IN COMPUTER SCIENCE. [Online]

Available at: http://www.computerscienceonline.org/csprograms-for-women/ [Accessed 1st April 2015].

[7]. Wyatt, C., 2014. The Top 5 Benefits of Gender Diversity in the Workplace. [Online]

Available at: http://www.ttidiversity.com/the-top-5-benefitsof-gender-diversity-in-the-workplace/ [Accessed 1st April 2015].

[8]. Career Builder, 2011. Top 6 Reasons to Earn A Computer Science Degree. [Online]

Available at: http://www.itcareerfinder.com/brainfood/blog/entry/top-reasons-to-earn-a-computer-sciencedegree.html [Accessed 1st April 2015].

[9]. Miller, A., 2014. Women in Science, Technology, Engineering and Mathematics (STEM) lecture series. Liverpool, Liverpool John Moores University.

[10]. YourLife, 2015. \{Online]

Available at: http://www.yourlife.org.uk/ [Accessed 11th October 2015].

[11]. Spertus, E., 1991. Why are There So Few Female Computer Scientists?, MA, USA: Massachusetts Institute of Technology Cambridge.

[12]. Lindberg, M., 2014. When Women Stop Coding. [Online]

Available at: http://www.aauw.org/2014/10/27/when-womenstop-coding/ [Accessed 27th March 2015].

[13]. Catalyst, 2015

Available at: http://www.catalyst.org/knowledge/genderdivide-tech-intensive-industries [Accessed 1st April 2015]. [14]. MPRnews, 2013. Women in tech industry open up about male behavior. [Online]

Available at: http://www.mprnews.org/story/2013/07/09/dailycircuit-tech-women [Accessed 27th March 2015].

[15]. Curtis, S., 2013. Women in IT should not feel like 'lone wolves,' says lobby group. [Online]

Available at: http://littlemissgeek.org/archives/866 [Accessed 27th March 2015].

[17]. Snyder, K., 2014. Why women leave tech: It's the culture, not because 'math is hard'. [Online]

Available at: http://fortune.com/2014/10/02/women-leavetech-culture [Accessed 27th March 2015].

[18]. Lynch, S., 2015. How Do You Get More Women into Technology?. [Online]

Available at: http://www.gsb.stanford.edu/insights/how-doyou-get-more-women-technology [Accessed 22nd February 2015]. 